\title{
Spontaneous Endogenous Core Temperature Rewarming After Cooling Due to Snow Burial
}

\author{
Colin K. Grissom, MD; Chris H. Harmston, MSE; John C. McAlpine, MD; Martin I. Radwin, MD; \\ Brad Ellington, DO; Ellie L. Hirshberg, MD; Andre Crouch, MD \\ From the Critical Care Medicine Division, Intermountain Medical Center, Murray, UT (Drs Grissom and Hirshberg); University of Utah, \\ Pulmonary and Critical Care Division, Department of Medicine, Salt Lake City, UT (Drs Grissom and Hirshberg); Sorenson Genomics, Salt \\ Lake City, UT (Mr Harmston); Department of Anesthesiology, Lions Gate Hospital, North Vancouver, BC, Canada (Dr McAlpine); Granger \\ Medical Clinic, Salt Lake City, UT (Dr Radwin); Emergency Department, Research Medical Center, Kansas City, MO (Dr Ellington); \\ University of Utah, Department of Pediatrics, Salt Lake City, UT (Dr Hirshberg); University of Utah, Division of Emergency Medicine, Salt \\ Lake City, UT (Dr Crouch).
}

Objective.-To measure afterdrop and rewarming in subjects placed in a hypothermia wrap immediately after extrication from 60 minutes of snow burial.

Methods.-We measured esophageal core body temperature (Tes) in 6 subjects buried in compacted snow (mean density 39\%) for up to 60 minutes at an altitude of $2450 \mathrm{~m}$ while breathing with an AvaLung (Black Diamond Equipment, Salt Lake City, UT). Mean snow temperature was $-3.5 \pm 1.0^{\circ} \mathrm{C}$ and mean air temperature was $0 \pm 2{ }^{\circ} \mathrm{C}$. Subjects wore a 1-piece Gore-Tex suit over medium weight Capilene underwear with a hood, face mask, goggles, mittens, and boots. After extrication from snow burial subjects were immediately placed in a hypothermia wrap. Tes was measured for an additional 60 minutes as subjects rewarmed by shivering.

Results.-Tes cooling rate during snow burial was $0.84 \pm 0.3^{\circ} \mathrm{C} / \mathrm{h}$ during a mean burial time of $58 \pm$ 4 minutes. Tes afterdrop $\left(0.77 \pm 0.4^{\circ} \mathrm{C}\right)$ occurred $12 \pm 8$ minutes after extrication from snow burial at a cooling rate of $4.0 \pm 0.8^{\circ} \mathrm{C} / \mathrm{h}(P<.001$ Tes snow burial vs afterdrop cooling rate). Rewarming rate was $1.1 \pm 0.3^{\circ} \mathrm{C} / \mathrm{h}$ over the subsequent $48 \pm 8$ minutes $(P=0.045$ snow burial cooling vs rewarming rate)

Conclusion.-Afterdrop rate increased about 4-fold as compared to snow burial cooling rate for a transient time period in subjects who were placed immediately into an insulating hypothermia wrap. Spontaneous endogenous rewarming increased core body temperature at a slightly higher rate than it decreased during snow burial. These findings suggest that field rewarming of mildly hypothermic and shivering avalanche burial victims is possible, but they should be insulated quickly to limit significant afterdrop.

Key words: accidental hypothermia, rewarming, avalanches, afterdrop

\section{Introduction}

Survivors of avalanche burial may be hypothermic ${ }^{1-3}$ and severity depends on duration of burial, but rate of core temperature cooling is not well defined. Knowledge of core temperature cooling rate would help predict severity of hypothermia and enable rescuers to better triage and treat avalanche burial victims. Mildly hypothermic avalanche burial victims could potentially be rewarmed in the field, while those with moderate or severe hypo-

Preliminary results from this study were presented at the 2005 Annual Meeting of the Wilderness Medical Society, Snowmass, CO, and at the 2006 International Snow Science Workshop, Telluride, CO.

Corresponding author: Colin K. Grissom, MD, Critical Care Medicine, Intermountain Medical Center, 5121 South Cottonwood St, Murray, UT, 84107 (e-mail: colin.grissom@imail.org). thermia would require rapid evacuation to a hospital for rewarming.

In a previous study we measured core body temperature cooling rate in mildly hypercapnic subjects buried in snow wearing a lightweight clothing insulation system and found that core body temperature cooling rate was 1.2 to $1.3^{\circ} \mathrm{C} / \mathrm{h} .{ }^{4}$ In a subsequent study we measured core body temperature afterdrop in mildly hypercapnic subjects extricated from 60 minutes of snow burial who ambulated $30 \mathrm{~m}$ to a warming shelter, and found that core temperature afterdrop cooling rate during the first 5 minutes after extrication from snow burial was $3.3^{\circ} \mathrm{C} / \mathrm{h}$, more than double the cooling rate of $1.3^{\circ} \mathrm{C} / \mathrm{h}$ during snow burial. ${ }^{5}$ This suggests afterdrop may significantly worsen hypothermia in extricated avalanche burial vic- 
tims and impair rewarming attempts in the field or during transport. However, the high rate of core temperature cooling during afterdrop in our previous study may have been due to ambulation of the subjects from the study site to a rewarming area, because exercise is known to increase afterdrop in studies of immersion hypothermia. ${ }^{6}$ We therefore designed this current study to measure core temperature afterdrop when subjects are immediately packaged in an insulating hypothermia wrap after extrication from snow burial.

Our previous studies also suggest that avalanche burial victims buried for periods of up to 1 hour, and who are extricated alive, should only have mild hypothermia (32$\left.36^{\circ} \mathrm{C}\right)$ if core body temperature was normal $\left(37^{\circ} \mathrm{C}\right)$ at the time of burial. Mildly hypothermic avalanche burial victims extricated alive should exhibit vigorous shivering. Studies of immersion hypothermia show that it is possible for mildly hypothermic persons to rewarm by shivering alone if dry insulation is provided, ${ }^{6}$ defined as spontaneous endogenous rewarming. ${ }^{7}$ We also designed this study to determine whether spontaneous endogenous rewarming could attenuate afterdrop and rewarm subjects after extrication from snow burial.

Our objective in this study was to measure core body temperature cooling rate in subjects buried in dense snow for up to 60 minutes while breathing with an artificial device (AvaLung 2, Black Diamond Equipment, Salt Lake City, UT), and then to measure afterdrop and rewarming rate as subjects were extricated from snow burial and placed immediately in an insulating hypothermia wrap and allowed to rewarm by shivering alone.

\section{Methods}

This study was performed at $2450 \mathrm{~m}$ elevation (average barometric pressure $571 \pm 3 \mathrm{~mm} \mathrm{Hg}$ ) at The Canyons ski resort in the Wasatch Mountains, Utah. Average ambient air temperature was $0 \pm 2{ }^{\circ} \mathrm{C}$ during the studies. The experimental set-up consisted of a large mound of snow compacted with body weight and allowed to age-harden for approximately 2 hours. Snow density was determined in multiple sites using a 1000 -cc wedge density cutter (Snowmetrics, Ft. Collins, CO) that measured the weight of water per cubic meter $\left(\mathrm{kg} / \mathrm{m}^{3}\right)$. Snow density is reported as a percent (ie, $300 \mathrm{~kg} / \mathrm{m}^{3}$ is $30 \%$ density snow). Mean snow density was $39 \pm 3 \%$. Snow temperature was measured with a dual thermocouple thermometer (Model 600-1040, Barnant Co, Barrington, IL). Mean snow temperature was $-3.5 \pm 1{ }^{\circ} \mathrm{C}$. A shoulder width trench was dug into one end of the snow mound and a sitting platform created for the subject so that the head would be approximately $50 \mathrm{~cm}$ under the top surface of the mound after burial. Figure 1 shows the experimental burial site with a subject during extrication at the end of a study burial. Subjects were fully buried in the snow for up to 60 minutes while breathing with an artificial device (AvaLung 2, Black Diamond Equipment, Salt Lake City, UT). After 60 minutes of snow burial subjects were extri-

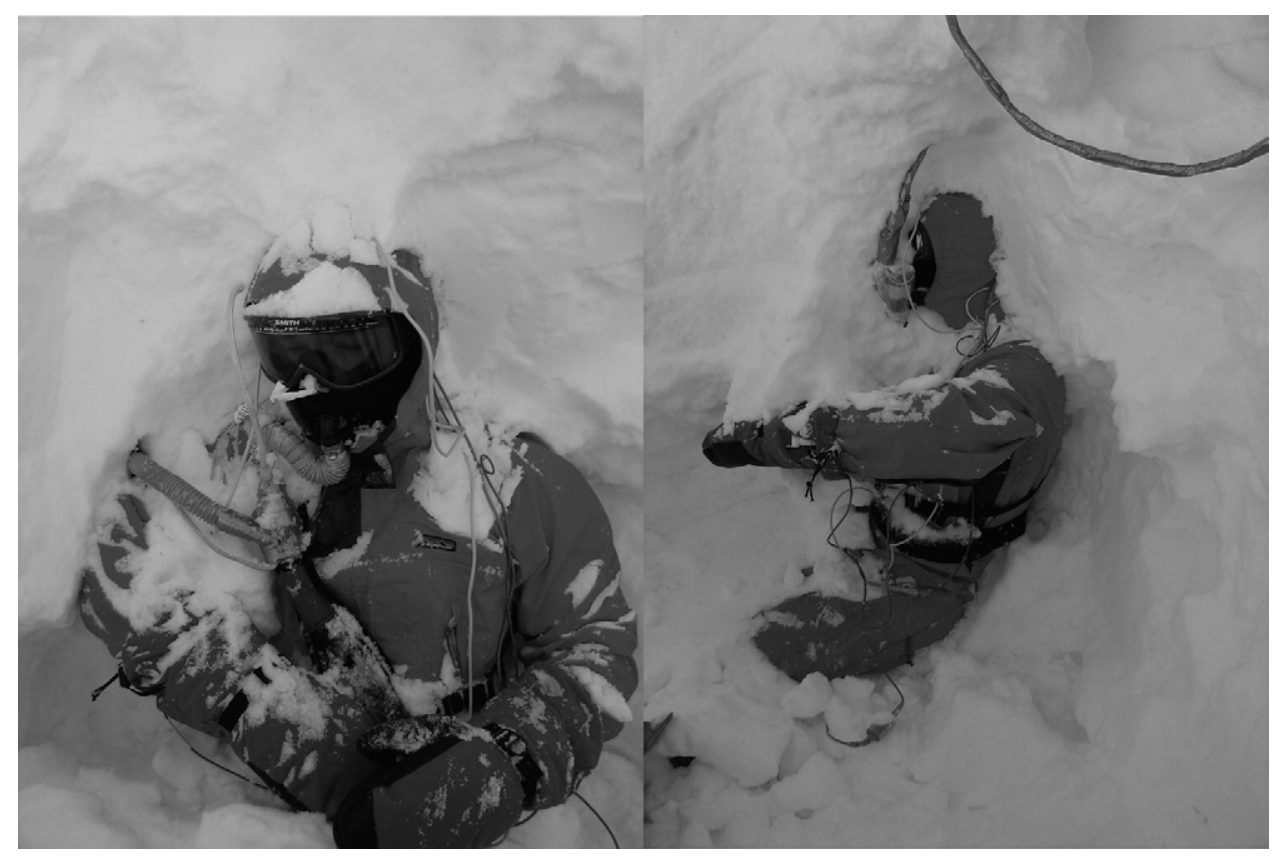

Figure 1. Front and side views of a subject during extrication at the end of a burial. 
cated and transferred to a hypothermia wrap where they were allowed to rewarm by shivering for 60 minutes.

Subjects were healthy paid volunteers, 3 women and 3 men, mean age $27 \pm 3$ years, mean height $174 \pm 5 \mathrm{~cm}$, mean weight $66 \pm 4 \mathrm{~kg}$, mean body mass index $22 \pm 1$. All subjects wore an identical lightweight clothing insulation system consisting of a 1-piece Gore-Tex suit (Patagonia, Ventura, CA) over medium weight Capilene underwear (Patagonia), a hood and facemask with goggles, mittens and warm boots. The Intermountain Healthcare Research and Human Rights Committee approved this study, and written informed consent was obtained from volunteers.

During snow burial subjects breathed through an artificial breathing device that draws inspired air from the snowpack in front of the subject's chest and diverts expired air into the snowpack behind the subject (Figure 2). This device is used by some persons traveling in avalanche terrain and is intended to prolong survival during avalanche burial (AvaLung 2). In a previous study our

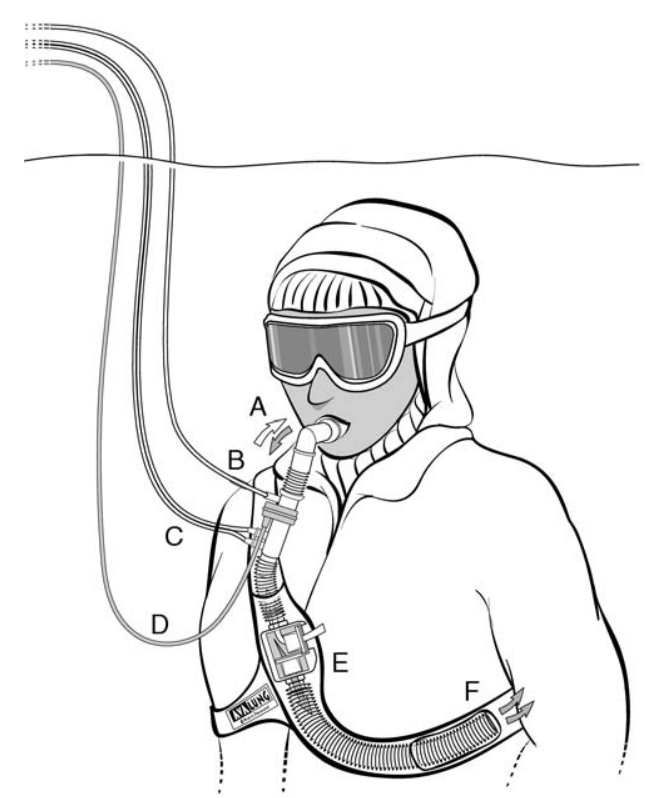

Figure 2. The breathing device used during the snow burial is shown (AvaLung 2). White arrows show flow of inspiratory air, and dark arrows show flow of expiratory air. The subject breathes in and out through the mouthpiece (A). An emergency oxygen back-up line (B) is attached directly into the mouthpiece apparatus and is used only if the subject becomes hypoxemic or requests to end the study. Monitoring lines $(\mathrm{C}, \mathrm{D})$ are connected to a device for measuring and recording inspired carbon dioxide, expired carbon dioxide, and minute ventilation. Inhaled air enters from the snowpack through the 1-way inspiratory valve on the side of the housing inside the mesh-protected harness on the chest (E). Expired air leaves the lungs through the mouthpiece and travels down the respiratory tubing to the housing and then passes through an expiratory 1-way valve located at the bottom of the housing (E) and travels via respiratory tubing inside the harness around to the back $(\mathrm{F})$. group demonstrated that subjects breathing with this device during snow burial maintained adequate oxygenation for up to 60 minutes but gradually developed hypercapnia. ${ }^{8}$

Physiologic parameters were continuously monitored during the burial studies and were recorded every minute. These parameters included esophageal core body temperature (Tes) in degrees celsius obtained by a probe inserted through the nose and into the esophagus with the tip at the level of the heart. Core body temperature was also measured with a rectal probe (Tre) inserted to 15 $\mathrm{cm}$. Esophageal and rectal temperature probes (model 401, YSI Inc, Yellow Springs, OH) were attached to a monitor (Propaq Encore, Protocol Systems Inc, Beaverton, OR) that also monitored surface 3 lead electrocardiogram (ECG). Ventilation parameters measured included partial pressure of end-tidal carbon dioxide $\left(\mathrm{ETCO}_{2}\right)$ and partial pressure of inspired carbon dioxide $\left(\mathrm{PICO}_{2}\right)$ in $\mathrm{mm} \mathrm{Hg}$, minute ventilation (VE) in $\mathrm{L} / \mathrm{min}$, and percent saturation of hemoglobin with oxygen $\left(\mathrm{SpO}_{2}\right)$ (CO2SMO Plus, model 8100, Novametrix, Wallingford, CT). Fraction of inspired carbon dioxide $\left(\mathrm{FICO}_{2}\right)$ was obtained by dividing $\mathrm{PICO}_{2}$ by ambient barometric pressure. Arterial oxygen saturation $\left(\mathrm{SpO}_{2}\right)$ was measured by 4 different pulse oximeters (Propaq Encore, CO2SMO Plus, and 2 Masimo SET Rad-5s, 1 with a finger and the other with a forehead probe, Masimo Corp, Irvine, CA).

Immediately prior to burial subjects made a brisk uphill walk for 5 minutes and then returned to the study area where they were rapidly buried while sitting in the snow mound trench and breathing on the mouthpiece of the artificial breathing device. Snow was rapidly and densely compacted around their bodies until they were completely buried and immobile. Study time was started when the subject's head was completely buried. During the burial subjects could communicate with the surface team via intercom at any time if necessary. The study burial was terminated after 60 minutes, or when $\mathrm{Spo}_{2}$ fell to $\leq 85 \%$, or when core temperature dropped below $35^{\circ} \mathrm{C}$, or at the subject's request. An emergency oxygen backup line was attached to the breathing device mouthpiece and could deliver $15 \mathrm{~L} / \mathrm{min}$ of $100 \%$ oxygen.

After 60 minutes of burial subjects were extricated from the snow (time 0 ) and immediately placed in a synthetic sleeping bag (custom made, rating $0^{\circ} \mathrm{C}$ ) wrapped in a wool blanket on an ensolite pad. A heavy plastic vapor barrier (6 mil black plastic $10 \times 10 \mathrm{ft}$ ) was then wrapped around the wool blanket, sleeping bag, and ensolite pad to complete the hypothermia wrap. Core body temperature was monitored for an additional 60 minutes. 


\section{STATISTICS}

All data were compared using time 0 of extrication so that if a subject's snow burial portion of the study was less than 60 minutes, their data were adjusted so that end burial occurred at time 0 (extrication) and the start of burial occurred at minus the number of minutes of the duration of their study burial. Both Tes and Tre were recorded and are reported for comparison, but only Tes is used for data analysis due to the known lag of Tre during rewarming.

Cooling rate in ${ }^{\circ} \mathrm{C} / \mathrm{h}$ was calculated arithmetically using the Tes at extrication and Tes at the time of burial. Afterdrop cooling rate in ${ }^{\circ} \mathrm{C} / \mathrm{h}$ was calculated arithmetically by using the nadir in afterdrop Tes and the Tes at extrication. Rewarming rate in ${ }^{\circ} \mathrm{C} / \mathrm{h}$ was calculated arithmetically by using the nadir in afterdrop Tes and the end study (60 minutes after extrication) Tes. Afterdrop cooling rate was compared to cooling rate during snow burial by a paired $t$ test. Cooling rate during snow burial and rewarming rate after the nadir of afterdrop were compared using a paired $t$ test. Statistica (StatSoft, 1999 ed, Tulsa, OK) software was used for all statistical analysis. $P<.05$ was considered statistically significant. Data are reported as mean \pm SD with $95 \%$ confidence intervals.

\section{Results}

Tes cooling rate (Table and Figure 3 ) during snow burial was $0.84 \pm 0.3^{\circ} \mathrm{C} / \mathrm{h}$ during a mean burial time of $58 \pm$ 4 minutes. Tes afterdrop occurred over $12 \pm 8$ minutes after extrication from snow burial with a Tes cooling rate of $4.0 \pm 0.8^{\circ} \mathrm{C} / \mathrm{h}(P<.001$ snow burial Tes cooling rate as compared to afterdrop cooling rate). Even though cooling rate during afterdrop was $4.0 \pm 0.8^{\circ} \mathrm{C} / \mathrm{h}$, the short duration $(12 \pm 8$ minutes) resulted in a mean afterdrop of $0.77 \pm 0.4^{\circ} \mathrm{C}$. Rewarming occurred after the nadir of the Tes afterdrop at a rate of $1.1 \pm 0.3^{\circ} \mathrm{C} / \mathrm{h}$ over the subsequent $48 \pm 8$ minutes during spontaneous en- dogenous rewarming ( $P=0.045$ snow burial cooling rate as compared to Tes endogenous rewarming rate).

Tre cooling rate (Table and Figure 3) during snow burial $\left(1.4 \pm 0.5^{\circ} \mathrm{C} / \mathrm{h}\right)$ was greater than Tes cooling rate $\left(0.84 \pm 0.3^{\circ} \mathrm{C} / \mathrm{h}\right)(P=0.026)$. Tre afterdrop was $0.65 \pm$ $0.5^{\circ} \mathrm{C}(P=0.4$ compared to Tes afterdrop) with a time to nadir at $26 \pm 15$ minutes $(P=.13$ compared to Tes time to afterdrop nadir). Tre afterdrop cooling rate was $1.8 \pm 1.9^{\circ} \mathrm{C} / \mathrm{h}(P=.073$ compared to Tes afterdrop cooling rate). Tre rewarming rate $\left(0.55 \pm 0.2^{\circ} \mathrm{C} / \mathrm{h}\right)$ significantly lagged behind Tes rewarming rate $(P=0.021)$.

During snow burial fraction of inspired $\mathrm{CO}_{2}$ increased from $0.4 \pm 0.6 \%$ to $4.9 \pm 2.1 \%(P=0.005), \mathrm{ETCO}_{2}$ increased from $38 \pm 2 \mathrm{~mm} \mathrm{Hg}$ to $52 \pm 10 \mathrm{~mm} \mathrm{Hg}(P=$ $0.03)$, and minute ventilation increased from $14 \pm 2$ $\mathrm{L} / \mathrm{min}$ to $33 \pm 9 \mathrm{~L} / \mathrm{min}(P=0.008)$. $\mathrm{SpO}_{2}$ decreased from $97 \pm 1 \%$ to $91 \pm 5 \%(P=0.02)$.

\section{Discussion}

We found that during burial in dense snow for up to 60 minutes core body temperature cooling rate was $0.84 \pm$ $0.3^{\circ} \mathrm{C} / \mathrm{h}$. After extrication from snow burial, afterdrop cooling rate significantly increased to more than four times the cooling rate during snow burial $\left(4.0 \pm 0.8^{\circ} \mathrm{C} /\right.$ h). Afterdrop was attenuated after just $12 \pm 8$ minutes, limiting afterdrop to $0.77 \pm 0.4^{\circ} \mathrm{C}$. Spontaneous endogenous rewarming increased core temperature at a slightly faster rate than it decreased during snow burial (rewarming rate $1.1 \pm 0.3^{\circ} \mathrm{C} / \mathrm{h}, P=0.045$ compared to cooling rate).

The Tes cooling rate during snow burial in this study $\left(0.84 \pm 0.3^{\circ} \mathrm{C} / \mathrm{h}\right)$ was lower than the Tre cooling rate $(1.4 \pm$ $0.5^{\circ} \mathrm{C} / \mathrm{h}$ ). In our previous studies using a similar snow burial protocol, Tre cooling rate was 1.2 to $1.3^{\circ} \mathrm{C} / \mathrm{h},{ }^{4,5}$ which is about the same Tre cooling rate observed in this study. This current study is the first to measure Tes cooling rate during snow burial. Tes is a more accurate

Table. Comparison of esophageal and rectal core temperature cooling and rewarming rates

\author{
Esophageal temperature (Tes) \\ Mean $\pm S D$ \\ (95\% confidence interval)
}

Rectal temperature (Tre)

Mean $\pm S D$

(95\% confidence interval)

\footnotetext{
Snow burial cooling rate $\left({ }^{\circ} \mathrm{C} / \mathrm{h}\right)$

Cooling duration (min)

Afterdrop $\left({ }^{\circ} \mathrm{C}\right)$

Afterdrop cooling rate $\left({ }^{\circ} \mathrm{C} / \mathrm{h}\right)$

Afterdrop duration (min)

Rewarming rate $\left({ }^{\circ} \mathrm{C} / \mathrm{h}\right)$
}

$$
\begin{gathered}
0.84 \pm 0.3(0.6-1.1) \\
58 \pm 4(55-61) \\
0.77 \pm 0.4(0.5-1.0) \\
4.0 \pm 0.8(3.4-4.6)^{b} \\
12 \pm 8(6-18) \\
1.1 \pm 0.3(0.9-1.3)
\end{gathered}
$$

$$
\begin{gathered}
1.4 \pm 0.5(1.0-1.8)^{a} \\
58 \pm 4(55-61) \\
0.65 \pm 0.5(0.3-1.0) \\
1.8 \pm 1.9(0.3-3.3) \\
26 \pm 15(14-38) \\
0.55 \pm 0.2(0.4-0.7)^{a}
\end{gathered}
$$

\footnotetext{
${ }^{a} P<.05$ comparison to Tes vs Tre.

${ }^{b} P<.05$ comparison Tes afterdrop vs snow burial cooling rate.
} 


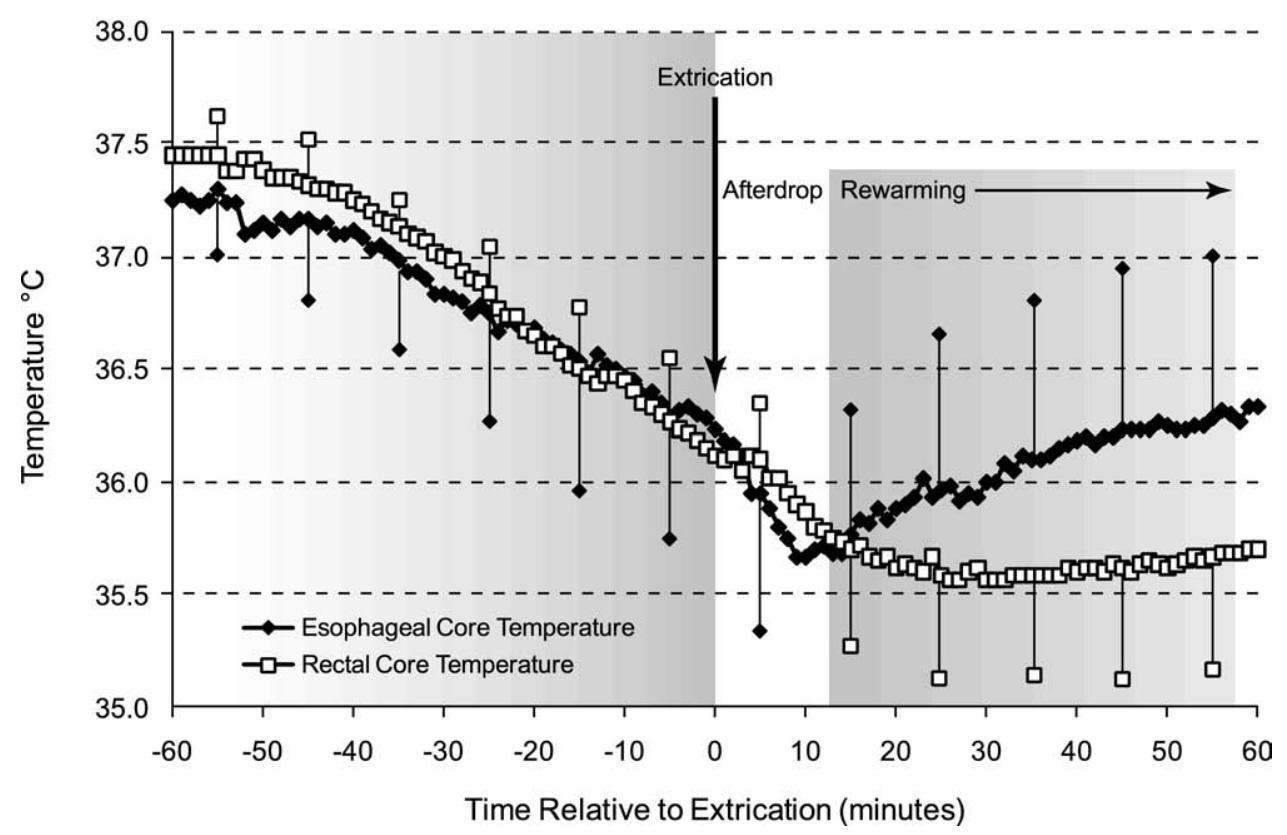

Figure 3. Esophageal (Tes $\bullet$ ) and rectal (Tre $\square$ ) core temperatures in ${ }^{\circ} \mathrm{C} \pm \mathrm{SD}$ during snow burial and after extrication during spontaneous endogenous rewarming. Time 0 is relative to extrication from snow burial. At extrication from snow burial both Tes and Tre show an afterdrop, but the afterdrop of Tes is attenuated and the Tes shows rewarming of the core as insulation is provided to the shivering subject. Tre lags behind Tes during rewarming representing temperature gradients from the body core to the body shell as rewarming occurs. The findings suggest that core cooling rates during avalanche burial will cause only mild hypothermia during burials of up to about 1 hour in duration, but significant afterdrop can occur in avalanche burial victims after they are extricated from snow burial and insulation should be provided as quickly as possible. Avalanche burial victims who are awake and shivering after extrication from snow burial can be rewarmed in the field by spontaneous endogenous rewarming (providing insulation and allowing shivering to rewarm the avalanche burial survivor).

measure of core temperature cooling because it more closely correlates with temperature of the heart. ${ }^{7,9}$ Tre, however, is a more easily measured temperature in the field or during initial evaluation in a hospital. The most significant difference between Tes and Tre occurs during the transition from cooling to rewarming. During this period Tes and heart temperature may be rising while Tre is still falling ${ }^{7,9,10}$ as was observed in our study. Relying on Tre measurements to guide treatment may lead to overly aggressive measures to rewarm a hypothermic patient. As our study demonstrates, despite the continued drop in Tre, spontaneous endogenous rewarming of the core, as measured by Tes, was occurring through shivering in a field setting. This lends support to the recommendation that esophageal temperature measurements be used for clinical decision making in extricated avalanche burial victims. ${ }^{1}$ Measurement of tympanic membrane temperature may also be used but requires a thermocouple probe with a cotton tip that is placed directly on the tympanic membrane, and its accuracy in a field setting is controversial. ${ }^{11}$ Infrared tympanic thermometers are not recommended for field diagnosis because of inaccuracy due to environmental conditions. ${ }^{7}$

The findings in our study suggest that a mildly hypothermic and shivering avalanche burial survivor can be rewarmed in the field if adequate insulation is provided. Our study also suggests that providing insulation as soon as possible to an avalanche burial victim is important to limit afterdrop. The likely mechanism for the increased cooling rate during afterdrop in our study is increased activity by the subject upon extrication from snow burial as compared to total immobilization in dense compacted snow during burial. During extrication in our study the level of activity of subjects was minimal and consisted of moving the extremities to help free themselves. The rapid increase in core temperature cooling rate during extrication from snow burial was reported previously by our group using $\mathrm{Tre}^{5}$ in subjects who ambulated after extrication. The study we report here is the first to measure Tes afterdrop rates after extrication from snow burial. Despite measures to limit activity, and afterdrop, by keeping subjects supine and immediately placing them in a hypothermia wrap, afterdrop cooling rate still significantly accelerated as compared to snow burial cooling rate, which has implications for treatment of hypothermic avalanche burial survivors.

The Tes afterdrop in this study $\left(0.77 \pm 0.4^{\circ} \mathrm{C}\right)$ is greater than reported by Giesbrecht et $\mathrm{al}^{6}$ in subjects cooled in $8^{\circ} \mathrm{C}$ water and then rewarmed by shivering with insulation provided (afterdrop $0.33 \pm 0.24^{\circ} \mathrm{C}$ ) but 
of similar duration ( $12 \pm 8$ minutes in our study vs $14 \pm$ 7 minutes). The afterdrop in this study is lower than that reported by Giesbrecht and colleagues ${ }^{6}$ in subjects cooled in $8^{\circ} \mathrm{C}$ water and then rewarmed by exercising (afterdrop $0.9 \pm 0.3$ of duration $27 \pm 11$ minutes). Interestingly, the afterdrop rate in this study (4.0 \pm $0.8^{\circ} \mathrm{C} / \mathrm{h}$ ) is much higher than afterdrop cooling rates reported by Giesbrecht et $\mathrm{al}^{6}\left(1.4-2.0^{\circ} \mathrm{C} / \mathrm{h}\right)$. The increased afterdrop cooling rate in our study is similar to the increased cooling rate observed after circulation to a limb is temporarily occluded, then restored, during cold water immersion. ${ }^{12} \mathrm{We}$ speculate that convective cooling was the mechanism for afterdrop in our study; increased circulation to cold extremities during extraction cooled the blood and then after circulation back to the heart caused further cooling of the core. ${ }^{13}$ The findings in our study also suggest that extrication after cooling during snow burial results in a very high afterdrop cooling rate.

Our findings from this small descriptive study suggest that avalanche burial victims should be kept supine and insulated in a hypothermia wrap as quickly as possible after extrication from snow burial in order to limit afterdrop and potential complications from hypothermia. Although increased physical activity after extrication from avalanche burial should be avoided in order to limit afterdrop, this is not always possible for safety or logistical reasons, and extricated avalanche victims may need to ambulate in order to move to a location away from further avalanche danger or self evacuate from a backcountry location when a rescue litter and rescue team are not available. In a previous study ${ }^{5}$ we determined the Tre afterdrop that would occur in rescued avalanche burial victims who ambulate for short distances. Interestingly, the Tre afterdrop was similar in the two studies: $0.65 \pm 0.5^{\circ} \mathrm{C}$ at $26 \pm 15$ minutes in our current study, and $0.69 \pm 0.4^{\circ} \mathrm{C}$ at $21 \pm 8$ minutes in our previous study. The findings in our current study demonstrate that Tes has a shorter duration of afterdrop than Tre, and an increased rewarming rate.

Hypothermia and trauma are the major medical problems requiring treatment in survivors of avalanche burial. Knowledge of core temperature cooling rate during avalanche burial would help rescue personnel estimate the severity of hypothermia and provide appropriate treatment for survivors. Few previous studies report core body temperature cooling rate during avalanche burial. Locher and Walpoth retrospectively studied 32 avalanche accidents where mean burial times and mean transport times to the hospital were over 60 minutes, and estimated that core body temperature cooling rate averaged $3{ }^{\circ} \mathrm{C} / \mathrm{h}$ from the time of burial in the avalanche to arrival at a hospital. ${ }^{14}$ In the study that we report here, and in previous studies, we observed a lower core temperature cooling rate during snow burial of 0.8 to $1.3^{\circ} \mathrm{C} /$ h. ${ }^{4,5}$ The difference in cooling rates between our studies and that of Locher and Walpoth might be explained by afterdrop. The higher core temperature cooling rate reported by Locher and Walpoth included cooling during avalanche burial and after extrication during transport to a hospital. Cooling rate may have been higher after extrication due to core temperature afterdrop. Brugger and colleagues ${ }^{2}$ reported clinical observations of rapid core temperature afterdrop in extricated avalanche burial victims, which is supported by the findings in our study.

Cooling rates reported from actual avalanche burial victims have varied from lower to higher than the cooling rates reported in our study. A 25-year-old male snowboarder survived avalanche burial for 20 hours with a large air pocket in front of his body and at the time of extrication had a core body temperature of $25.6^{\circ} \mathrm{C}$ (tympanic) in $-5^{\circ} \mathrm{C}$ snow, giving a core body temperature cooling rate of $0.6^{\circ} \mathrm{C} /$ h. ${ }^{4}$ In contrast, a 29 -year-old backcountry skier breathing into an airpocket survived a 100-minute avalanche burial at a depth of $3 \mathrm{~m}$ and had a core temperature on extrication of $22^{\circ} \mathrm{C}$ (tympanic), giving a cooling rate of approximately $9^{\circ} \mathrm{C} / \mathrm{h} .{ }^{15}$ These contrasting examples of actual core cooling rate during avalanche burial demonstrate that many factors contribute to core cooling rate, including snow temperature, insulation, physiologic status of the avalanche victim, and traumatic injuries that may predispose to hypothermia because of impaired thermogenesis.

Our study has significant limitations for application to rescue and medical care of actual avalanche burial victims. In the controlled experimental set up in our study, some factors that may occur in actual avalanche burial cannot be duplicated for safety reasons and core temperature cooling rate during actual avalanche burial may vary more than in our study. Avalanche burial victims may be unconscious or have traumatic injuries that could influence thermoregulation and increase core temperature cooling rate. Differences in clothing insulation may increase or decrease core temperature cooling rate. During prolonged burial core temperature cooling rate may not be linear and may plateau or accelerate below the core temperatures observed in our study. Persons buried in an avalanche may become more hypoxic than the subjects in our study, which may further accelerate core temperature cooling rate because hypoxia, independent of hypercapnia, can accelerate core temperature cooling rate. ${ }^{16}$

The artificial breathing device used in our study is worn by some persons traveling in high-risk avalanche terrain for use as an emergency breathing device if they are caught and buried in an avalanche. Survival after avalanche burial using this device has occurred. ${ }^{17}$ The results from our study may be applied by rescue personnel to estimate the severity of hypothermia in persons using this device for breathing after avalanche burial. 
Our study suggests that uninjured avalanche burial victims with an artificial breathing device who are extricated within an hour may only be mildly hypothermic and can be rewarmed in the field. In contrast, the results of our study may not be directly applicable to avalanche burial victims with a natural air pocket.

\section{Conclusions}

Core body temperature cooling rate after extrication from snow burial increased about 4-fold for a transient time period in subjects who were placed as quickly as possible into an insulating hypothermia wrap, but afterdrop was attenuated after a mean of only 12 minutes. Spontaneous endogenous rewarming from shivering alone increased core body temperature at a slightly higher rate than it decreased during snow burial. This suggests that field rewarming of avalanche burial victims with mild hypothermia who are shivering is possible, but they should be insulated quickly to limit the significant afterdrop that can occur. An accelerated afterdrop cooling rate places avalanche burial survivors at greater risk of complications due to hypothermia. This is important information for rescue personnel who should keep the avalanche burial victim supine and provide insulation as quickly as possible in order to prevent further heat loss after extrication from the snow.

\section{Financial Disclosures}

Colin K. Grissom and Chris H. Harmston are consultants for Black Diamond Equipment, Ltd, the manufacturer of the AvaLung (the artificial breathing device used in this study). Chris H. Harmston is a former employee of Black Diamond Equipment, Ltd. None of the other authors have any current or prior employment or consultant relationship with Black Diamond Equipment, Ltd. None of the authors own shares of Black Diamond Equipment, Ltd. None of the authors own any patent related to the AvaLung.

\section{Acknowledgments}

This study was supported by grants from The Heart \& Lung Foundation of the Deseret Foundation, Intermountain Healthcare, Salt Lake City, UT, and by a grant from the Wilderness Medical Society. The authors thank Black Diamond Equipment, Ltd., for donating the artificial breathing device, the AvaLung, for use in this study; and The Canyons ski resort for allowing us to conduct this study at their ski area. The authors also thank Abigail Wright Grissom for critical review of the manuscript.

\section{References}

1. Brugger H, Durrer B. On-site treatment of avalanche victims ICAR-MEDCOM-Recommendations. High Altitude Med Biol. 2002;3:421-425.

2. Brugger H, Durrer B, Adler-Kastner L. On-site triage of avalanche victims with asystole by the emergency doctor. Resuscitation. 1996;31:11-16.

3. Brugger H, Durrer B, Adler-Kastner L, Falk M, Tschirky F. Field management of avalanche victims. Resuscitation. 2001;51:7-15.

4. Grissom CK, Radwin MI, Scholand MB, Harmston CH, Muetterties MC, Bywater TJ. Hypercapnia increases core temperature cooling rate during snow burial. J Appl Physiol. 2004;96:1365-1370.

5. Grissom CK, McAlpine JC, Harmston CH, et al. Hypercapnia effect on core cooling and shivering threshold during snow burial. Aviat Space Environ Med. 2008;79:735-742.

6. Giesbrecht GG, Bristow GK, Uin A, Ready AE, Jones RA. Effectiveness of three field treatments for induced mild (33.0 degrees C) hypothermia. J Appl Physiol. 1987;63: 2375-2379.

7. Giesbrecht GG. Cold stress, near drowning and accidental hypothermia: a review. Aviat Space Environ Med. 2000; 71:733-752.

8. Grissom CK, Radwin MI, Harmston CH, Hirshberg EL, Crowley TJ. Respiration during snow burial using an artificial air pocket. JAMA. 2000;283:2261-2271.

9. Hayward JS, Eckerson JD, Kemna D. Thermal and cardiovascular changes during three methods of resuscitation from mild hypothermia. Resuscitation. 1984;11:21-33.

10. Goheen MS, Ducharme MB, Kenny GP, et al. Efficacy of forced-air and inhalation rewarming by using a human model for severe hypothermia. J Appl Physiol. 1997;83: 1635-1640.

11. Radwin MI, Grissom CK, Giesbrecht G. The rate of cooling during avalanche burial; a "core" issue. Resuscitation. 2009;80:956-957.

12. Mittleman KD, Mekjavic IB. Effect of occluded venous return on core temperature during cold water immersion. J Appl Physiol. 1988;65:2709-2713.

13. Giesbrecht GG, Bristow GK. A second postcooling afterdrop: more evidence for a convective mechanism. J Appl Physiol. 1992;73:1253-1258.

14. Locher T, Walpoth BH. Differential diagnosis of circulatory failure in hypothermic avalanche victims: retrospective analysis of 32 avalanche accidents. Schweiz Rundsch Med Prax. 1996;85:1275-1282.

15. Oberhammer R, Beikircher W, Hormann C, et al. Full recovery of an avalanche victim with profound hypothermia and prolonged cardiac arrest treated by extracorporeal re-warming. Resuscitation. 2008;76:474-480.

16. Johnston CE, White MD, Wu M, Bristow GK, Giesbrecht GG. Eucapnic hypoxia lowers human cold thermoregulatory response thresholds and accelerates core cooling. J Appl Physiol. 1996;80:422-429.

17. Radwin MI, Grissom CK. Technological advances in avalanche survival. Wilderness Environ Med. 2002;13:143-152. 